\title{
The natural dietary genistein boosts bacteriophage-mediated cancer cell killing by improving phage-targeted tumor cell transduction
}

\author{
Effrosyni Tsafa $^{1}$, Mariam Al-Bahrani ${ }^{1}$, Kaoutar Bentayebi ${ }^{2}$, Justyna Przystal ${ }^{1}$, \\ Keittisak Suwan' ${ }^{1}$, Amin Hajitou ${ }^{1}$ \\ ${ }^{1}$ Phage Therapy Group, Department of Medicine, Imperial College London, Hammersmith Hospital Campus, London, \\ United Kingdom \\ ${ }^{2}$ Biotechnology Laboratory (Medbiotech), Medical and Pharmacy School, University Mohammed V de Rabat, Rabat, Morocco \\ Correspondence to: Amin Hajitou, email: a.hajitou@imperial.ac.uk
}

Keywords: bacteriophage display, genistein, cancer therapy, isoflavone, phage therapy

Received: November 24, 2015

Accepted: June 16, 2016

Published: July 18, 2016

\section{ABSTRACT}

Gene therapy has long been regarded as a promising treatment for cancer. However, cancer gene therapy is still facing the challenge of targeting gene delivery vectors specifically to tumors when administered via clinically acceptable noninvasive systemic routes (i.e. intravenous). The bacteria virus, bacteriophage (phage), represents a new generation of promising vectors in systemic gene delivery since their targeting can be achieved through phage capsid display ligands, which enable them to home to specific tumor receptors without the need to ablate any native eukaryotic tropism. We have previously reported a tumor specific bacteriophage vector named adeno-associated virus/phage, or AAVP, in which gene expression is under a recombinant human rAAV2 virus genome targeted to tumors via a ligand-directed phage capsid. However, cancer gene therapy with this tumor-targeted vector achieved variable outcomes ranging from tumor regression to no effect in both experimental and natural preclinical models. Herein, we hypothesized that combining the natural dietary genistein, with proven anticancer activity, would improve bacteriophage anticancer safe therapy. We show that combination treatment with genistein and AAVP increased targeted cancer cell killing by AAVP carrying the gene for Herpes simplex virus thymidine kinase (HSVtk) in 2D tissue cultures and 3D tumor spheroids. We found this increased tumor cell killing was associated with enhanced AAVPmediated gene expression. Next, we established that genistein protects AAVP against proteasome degradation and enhances vector genome accumulation in the nucleus. Combination of genistein and phage-guided virotherapy is a safe and promising strategy that should be considered in anticancer therapy with AAVP.

\section{INTRODUCTION}

Cancer is a major cause of mortality and morbidity worldwide despite progress in the conventional therapies and despite the fact that several mechanisms of oncogenesis are now understood. Developing efficient systemic therapies would play a major advance in cancer treatment. Indeed, most cancer patients die of metastases and systemic chemotherapy is the most widely used treatment for cancer. The major obstacle to the success of chemotherapy in cancer treatment is the development of tumor drug resistance. In addition, chemotherapy is not specific and the dose of the drug that reaches the tumor may be as little as $5 \%-10 \%$ of the total dose as it accumulates in normal organs [1].

Cancer gene therapy is a promising approach for cancer treatment. Gene therapy was initially conceived as a treatment for inherited diseases, but today up to $70 \%$ of clinical trials of gene therapy are designed to treat cancer. Gene therapy uses carriers called vectors to deliver the therapeutic gene to the patient's target cells. Currently, the most common vectors are eukaryotic viruses because they can enter cells as part of the natural infection process. Eukaryotic viruses are, unquestionably, superior 
vectors for gene transfer, but have had limited success in systemic gene therapy as they are taken up by the liver and reticulo-endothelial system, they have broad tropism for healthy tissues and they may lose efficacy due to the presence of neutralising antibodies [2]. A local vector delivery through intra-tumoral injection can be used to show proof of efficacy, but in practice clinical benefit for cancer treatment can only be achieved following systemic administration.

In 2006, we were the first to describe a novel systemic gene therapy vector based on bacteriophage (phage) that showed successful targeting of gene delivery to tumors in preclinical models of cancer following intravenous administration. We named this vector adenoassociated virus/phage or AAV/phage (AAVP) [3]. One advantage of using phage vectors over animal viral vectors is that bacteriophage has a safety history profile as it was given to humans to treat bacterial infections, and was approved in 2006 by the US Food and Drug Administration for use as safe antibacterial food additive [4]. Other advantages of phage vectors are their large cloning capacity as well as their simple and economical large-scale production and purification [5]. Finally, phage vectors are easily targetable through tissue specific ligands displayed on their capsid, without the need to ablate any native mammalian tropism. Phage display technology has largely shown that ligands displayed on the phage coat proteins remain intact and preserve their receptor binding properties [6]. Bacteriophage can infect and express genes in bacteria only. Thus the mammalian transgene cassette flanked by full length inverted terminal repeats (ITRs) from the recombinant adeno-associated virus (rAAV), which is mammalian single-stranded DNA virus, was genetically incorporated into the phage singlestranded genome [7]. This hybrid vector (AAVP) has no AAV capsid but phage capsid served to package the hybrid single-stranded genome. As phage has no tropism for mammalian cells, the gene encoding the pIII minor coat protein of the phage was genetically manipulated to display, as a fusion, the cyclic CDCRGDCFC (RGD4C) ligand that allows targeting of the phage capsid to tumors through binding to its $\alpha_{\mathrm{v}}$ integrin receptors which are specifically expressed on tumors but barely detectable on the healthy tissues. Consequently, the tumor-targeted RGD4C-AAVP achieved specific gene expression within tumors after intravenous administration resulting in strong antitumor effects in rodents, without harming the healthy tissues $[3,7,8]$. Remarkably, a study carried out by the National Cancer Institute, NCI-USA, with targeted RGD4C-AAVP-TNF $\alpha$ carrying the gene for the cytokine tumor necrosis factor alpha (TNF $\alpha)$, showed specific delivery of TNF $\alpha$ in natural tumors in pet dogs, resulting in eradication of aggressive and sizeable tumors such as fibrosarcoma in a few cases [9]. In brief, RGD4C-AAVP is a novel and promising systemic vector for cancer treatment.
However, while some preclinical studies showed remarkable outcomes, vector performance was also poor in some cases. One reason could be associated with poor intracellular trafficking of the vector as RGD4C-AAVP is still a bacteria virus that has not evolved to deliver genes to mammalian cells. We have previously investigated the intracellular trafficking of RGD4C-AAVP in cancer cells and uncovered barriers to gene delivery by RGD4CAAVP, such as weak phage attachment to the cell surface [10], poor endosomal escape [11], proteasome degradation [12] and nuclear transport (unpublished data). Proteasome inhibiting drugs and endosmolytic agents could be used to assist the phage to overcome intracellular barriers and subsequently enhance gene delivery. However, these drugs are not usually clinically applicable and have to be used at toxic pharmacological doses in order to be efficient. Anticancer treatment strategies such as conventional chemotherapy have been used to enhance gene therapy [13] and can be tested in combination with RGD4C-AAVP. However, chemotherapy is an invasive and toxic treatment with ferocious chemistry unable to differentiate between cancerous and healthy cells [1]. Herein, we postulated that the natural non-toxic dietary plant product, genistein, with proven anticancer activity can be used to enhance the RGD4C-AAVP-mediated tumor cell killing while preserving its safety attribute. Genistein is an isoflavone present in soy [14], that inhibits the growth and development of several malignancies [15-17]. Epidemiological studies have shown that a soy-rich diet is associated with low risk of breast and prostate cancer [18]. Genistein has already been used in clinical trials to investigate combined therapy of genistein and gemcitabine for the treatment of breast cancer patients and to evaluate genistein together with gemcitabine and erlotinib for the treatment of pancreatic cancer patients $[19,20]$. Genistein has similar structure to $17 \beta$-estradiol presenting weak estrogenic activity and can compete with $17 \beta$-estradiol for the estrogen receptor (ER), thus contributing to the treatment of hormone-related cancers [18]. Other mechanisms mediating the anticancer effect of genistein include the inhibition of mitogen activated protein kinase (MAPK) activation resulting in sensitizing human hepatocellular carcinoma Hep3B cells to TNFrelated apoptosis inducing ligand TRAIL-mediated apoptosis [21] and also induction of apoptosis in primary gastric cells by downregulating the antiapoptotic protein B cell lymphoma2 (Bcl-2) and upregulating the proapoptotic Bcl-2 associated X protein (Bax) [22]. Genistein also targets caspases, extracellular signalregulated kinases 1/2 (ERK1/2), nuclear transcription factor $\kappa \mathrm{B}(\mathrm{NF}-\kappa \mathrm{B})$, Wingless and integration $1 \beta$-catenin (Wnt/ $\beta$-catenin), phosphoinositide 3 kinase/Akt (PI3K/ Akt) and epidermal growth factor receptor protein tyrosine kinase (EGFR-PTK) signalling pathways resulting in anticancer and therapeutic effects [15]. 
Furthermore, genistein was shown to increase AAV2mediated transduction efficiency [23, 24]. Importantly, genistein can interfere with cellular pathways and, as a result, can be used to enhance the gene transfer efficacy of RGD4C-AAVP. For instance, the ability of genistein to inhibit the chymotrypsin-like activity of proteasome [25], can be used to prevent AAVP degradation by the proteasome. Moreover, the ability of genistein to induce G2/M cell cycle arrest could result in increased nuclear transport of gene therapy vectors [26-28]. Consequently, taking into account the safety of genistein, its anticancer activity and interference with cellular pathways, we hypothesized that combination of genistein with our tumor-targeted RGD4C-AAVP biotherapeutic particle would lead to enhanced tumor cell killing along with reduced toxicity. We also examined the effects of genistein on targeted gene transfer by RGD4C-AAVP in vitro and in tumor spheroid models, and investigated the mechanism of genistein's effects on RGD4AC-AAVP.

\section{RESULTS}

\section{Genistein drug treatment boosts cancer cell death by phage-mediated suicide gene killing}

First, we sought to assess the cytotoxicity of genistein in vitro on 9L rat glioblastoma and M21 human melanoma cell lines. These tumor cells were treated with increasing concentrations of genistein ranging from 50 to $3300 \mu \mathrm{M}$ for 2 hours and compared to non-treated cells. Subsequently, cell survival was assessed at 48 hours post drug treatment. The data show that tumor cell death raised as the concentration of the drug increased (Figure 1) in both 9L and M21 cancer cells with a more pronounced effect on the 9L glioblastoma cells than M21 melanoma cells. Cytotoxic doses expressed as $\mathrm{IC}_{50}$ values, showing the inhibitory concentrations required to induce the cell death by $50 \%$, are shown in Table 1 . We found that $50 \%$ of cell death in the presence of genistein was induced by $\sim 438.5 \mu \mathrm{M}$ in 9Lcells (Table 1), while in M21 cells, 50\% of cell death was achieved at a dose of over $1148 \mu \mathrm{M}$ (Table 1). Next, to assess the effect on tumor cell killing by RGD4C-AAVP, we selected genistein concentration of $150 \mu \mathrm{M}$ for both $9 \mathrm{~L}$ and M21 cancer cells, as this dose is below the $\mathrm{IC}_{50}$, causes little toxicity and was previously reported to enhance gene delivery by eukaryotic viral vectors [24].

To test tumor cell killing efficacy, we used the RGD4C-AAVP vector (RGD-HSVtk) encoding the gene for the herpes simplex virus type I thymidine kinase (HSVtk) mutant SR39 [29] which kills cells in the presence of ganciclovir, GCV (Figure 2). 9L and M21 cells were transduced with RGD-HSVtk or control nontargeted vector fd-HSVtk (without RGD4C) carrying the HSVtk gene with or without 2 hours pretreatment with genistein. The cells were then treated with GCV $(20 \mu \mathrm{M})$ at day 3 post vector transduction. Cancer cell killing was quantified at $0,24,48,72,96$ hours post GCV treatment. Results were normalized to non-targeted vector which did not show any tumor cell death (data not shown). In both cancer cell lines, the combination treatment with genistein and RGD-HSVtk therapy resulted in greater cell killing compared to cells treated with RGD-HSVtk or genistein drug alone (Figure 2). For instance, at $72 \mathrm{hrs}$ post GCV treatment, combination treatment induced $91.6 \%$ and $70.5 \%$ killing of 9L and M21 cancer cells, respectively (Figure 2), compared to $79.5 \%$ and $44.7 \%$ death induced by RGD-HSVtk vector alone in 9L and M21 cells, respectively, and $69.8 \%$ death and $49.6 \%$ death induced by genistein alone in 9L and M21 cells, respectively. These data show that drug treatment of cancer cells with an isoflavone is a promising approach to enhance targeted gene therapy by RGD4C-AAVP.

\section{Genistein increases targeted reporter gene transfer by the RGD4C-AAVP in 9L and M21 cancer cells in vitro}

To gain insight into the improved tumor cell killing by RGD-HSVtk following combination with genistein, we investigated the effect of genistein on gene delivery by RGD4C-AAVP. We first conducted qualitative analyses of transgene expression by using vectors carrying the reporter gene of the green fluorescent protein (RGD-GFP) and combined with 2 hours pretreatment with $150 \mu \mathrm{M}$ of genistein (Figure 3). Fluorescent microscopic analysis of GFP expression at day 4 post vector transduction showed that combination treatment with RGD-GFP and genistein resulted in significantly higher GFP expression, compared to RGD-GFP vector alone in both 9L and M21 tumor cells (Figure 3A-3D). Next, to confirm the increased gene delivery by RGD4C-AAVP in combination with genistein, we carried out a quantitative analysis of transgene expression over a time course of 4 days post vector transduction by using RGD4C-AAVP vectors expressing the firefly luciferase reporter gene, RGD-Luc, (Figure 3E and $3 \mathrm{~F}$ ). Consistently with GFP reporter transgene expression experiments, we observed a significant increase in luciferase expression by RGD-Luc vector at various time points post vector transduction by genistein treatment in both 9L and M21 cancer cells compared to cells treated with the vector alone. For instance at day 4 post transduction, combination treatment (RGD-Luc + Genistein) resulted in $\sim 4.7$ fold and $\sim 3.8$ fold increase in luciferase expression in 9L and M21 cells, respectively, compared to RGD-Luc treatment alone. Moreover, in 9L cells, initiation of the luciferase expression occurred as early as day 2 post vector transduction, in the presence of genistein (Figure 3E). Importantly, no luciferase expression was detected in cells transduced with nontargeted fd-Luc vector alone or in combination with genistein, which shows that genistein does not affect the specificity and targeting of the RGD4C-AAVP vector. 
Table 1: $\mathrm{IC}_{50}$ of genistein, curcumin, EGCG, bortezomib and carfilzomib in 9L and M21 cells

\begin{tabular}{|l|c|c|c|c|c|c|c|c|c|c|}
\hline \multicolumn{4}{|c|}{} & \multicolumn{4}{c|}{ 9L cells } & \multicolumn{4}{c}{ M21 cells } \\
\hline Cytotoxic agent & Genistein & Curcumin & EGCG & Bortezomib & Carfilzomib & Genistein & Curcumin & EGCG & Bortezomib & Carfilzomib \\
\hline $\mathrm{IC}_{50}(\mu \mathrm{M})$ & 438.5 & 35.05 & 203.7 & 1.55 & 1.034 & 1148 & 42.38 & 361.9 & 1 & 1.141 \\
\hline
\end{tabular}

Finally, we sought to investigate whether this enhanced AAVP gene delivery by genistein could also occur with other dietary phytochemicals. In this study we selected the phytochemicals curcumin and EGCG (epigallocatechin-3-gallate) known for their anticancer properties. First, we assessed the cytotoxicity of curcumin and EGCG on both 9L and M21 cells and determined the $\mathrm{IC}_{50}$ (Supplementary Figures 1 and 2, Table 1). Next, we used non-toxic doses of curcumin and EGCG below the $\mathrm{IC}_{50}($ Table 1$)$, and evaluated $9 \mathrm{~L}$ and M21 cell transduction
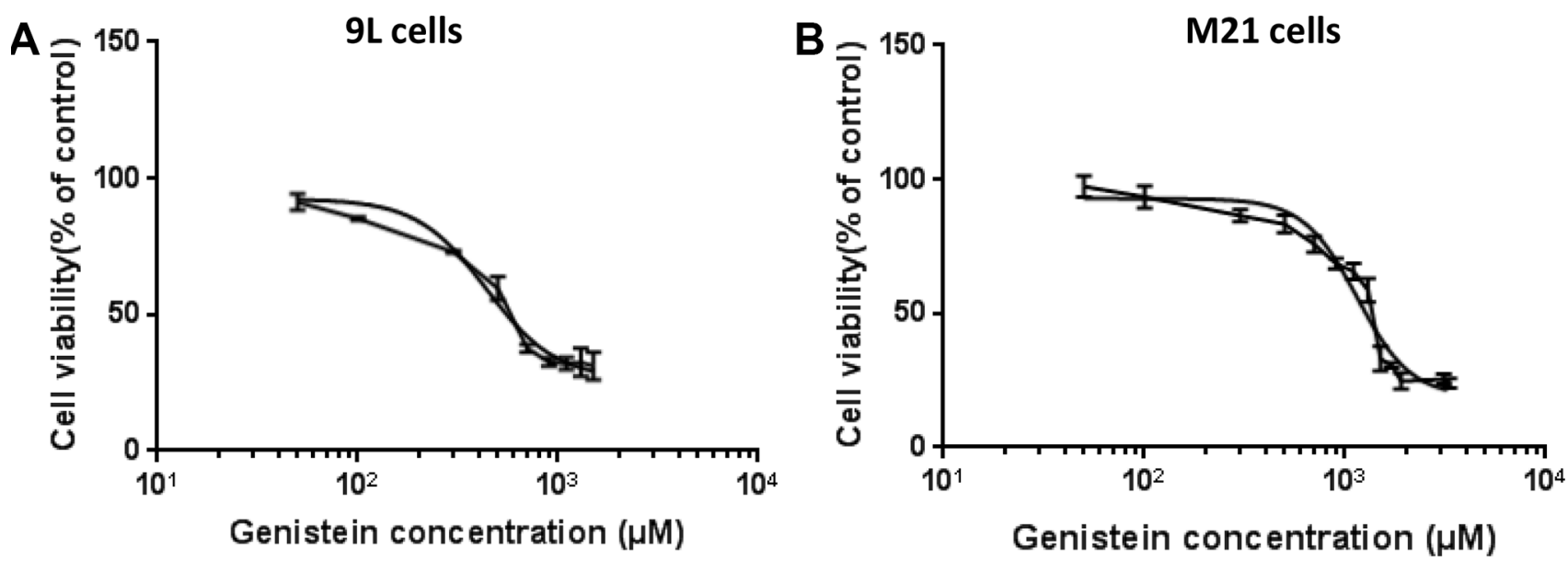

Figure 1: Cytotoxicity of genistein on 9L and M21 tumor cells. 9L (A) and M21 (B) cells were cultured in 96-well plates, then treated with increasing concentrations of genistein ranging from 50 to $3300 \mu \mathrm{M}$ for 2 hours. Next, cells were grown for further 48 hours without the drug. Cell survival was determined by using the MTT assay and expressed as percentage of cells counted in parallel cultures without the drug. The $\mathrm{IC}_{50}$ dose of genistein determined by GraphPad Prism using nonlinear regression was $438.5 \mu \mathrm{M}$ for $9 \mathrm{~L}$ cells and 1148 $\mu \mathrm{M}$ for $\mathrm{M} 21$ cells. The $\mathrm{X}$-axis is in the $\log (10)$ scale and the data fitted to Hill equation. The assay was repeated twice in triplicate and the results shown are representative of one experiment.
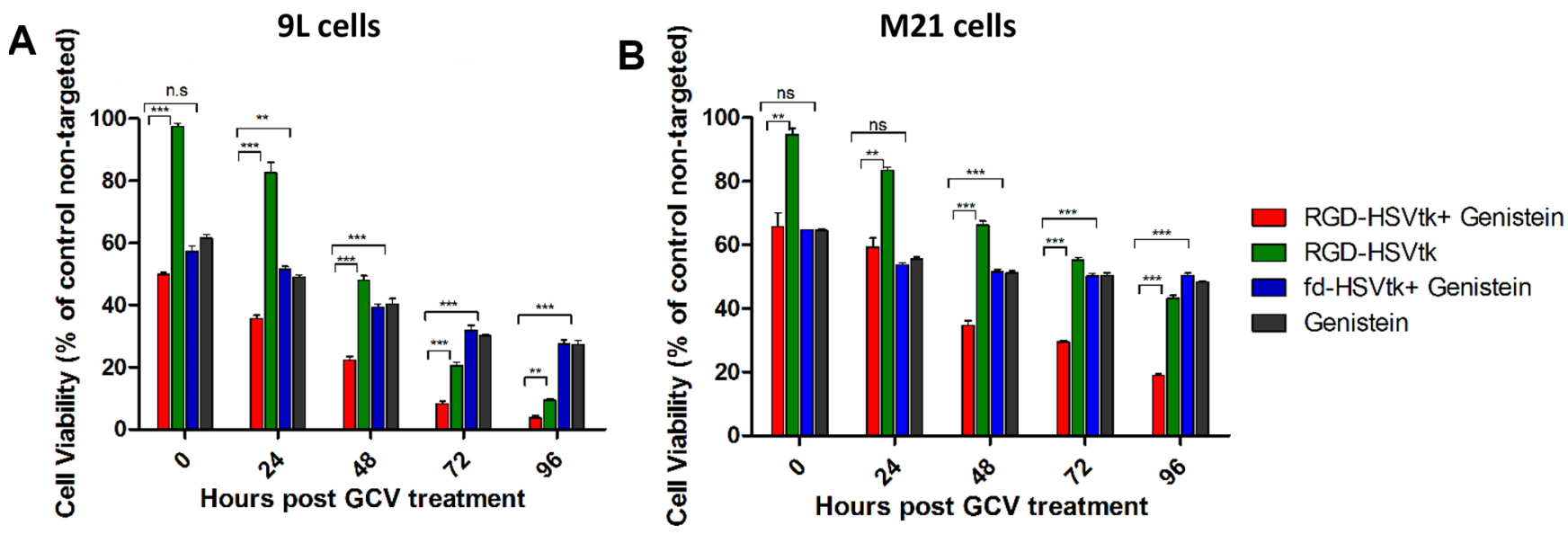

Figure 2: Genistein increased cell death of 9L and M21 tumor cells after transduction with RGD-HSVtk followed by GCV treatment. 9L (A) and M21 cells (B) grown in 48 well-plates (60-80\% confluent) were transduced with RGD-HSVtk targeted vector or control non-targeted fd-HSVtk vector with or without 2 hours pretreatment with genistein $(150 \mu \mathrm{M})$. The cells were treated with $\mathrm{GCV}(20 \mu \mathrm{M})$ at day 3 post vector transduction and renewed daily. Cancer cell killing was quantified at 0, 24, 48, 72, 96 hours post GCV treatment. Cells were counted by using the trypan blue exclusion methodology. Results are normalized to control non-targeted fd-HSVtk vector. The experiment was repeated twice in triplicate and the results shown are representative of one experiment. 
by RGD-Luc in combination with curcumin and EGCG. We found that curcumin increased the transduction efficiency of the targeted RGD-Luc in 9L cells, in a dose dependent manner (Supplementary Figure 1C), but not in the M21 cells (Supplementary Figure 1D). Importantly, no effect of curcumin was observed on the control nontargeted fd-Luc vector proving that curcumin did not affect the specificity of the targeted RGD-Luc vector. Finally treatment with EGCG did not increase the transduction efficiency of the RGD-Luc vector in both cell lines (Supplementary Figure 2).

\section{Evaluation of vector cellular entry following genistein pretreatment}

After demonstrating that the increased tumor cell killing by RGD4C-AAVP observed in combination with genistein was associated with enhanced RGD4C-AAVPmediated gene expression, we set out to gain further understanding into the mechanism of this enhanced gene transfer. Therefore, we sought to investigate the effect of genistein on steps involved in gene transfer. It is well established that vector-mediated gene delivery depends on several steps where the vector needs to access the cell surface to bind to its receptor, followed by cell internalization and intracellular trafficking, then transport to the nucleus for gene expression to occur $[30,31]$. We first examined the effect of genistein on vector attachment to the surface of cells, as we previously reported that gene transfer by RGD4C-AAVP is hindered by its weak accessibility to the surface of tumor cells [10]. Hence, we quantified the free cellunbound phage in the supernatant above the adherent cells by infection of host bacteria followed by colony counting (Figure 4A). An amount of $52 \%$, of input phage particles, was recovered from the supernatant of cells treated with the RGD-GFP vector showing that a fraction of $48 \%$ of input phage was bound to the surface of tumor cells. However, pretreatment with genistein had no effect on vector attachment to the cell surface (Figure 4A). The non-targeted fd-GFP vector showed no attachment to the surface of tumor cells with $100 \%$ recovery. Finally, internalization assays revealed that combination of vector with genistein did not increase entry of the RGD4C-AAVP into cancer cells (Figure 4B and $4 \mathrm{C}$ ). These data show that genistein has no effect on
9L cells

A

A

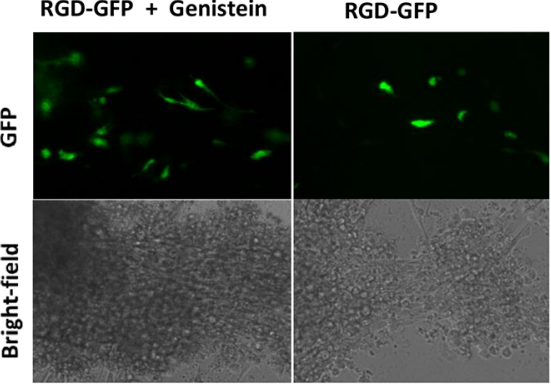

E

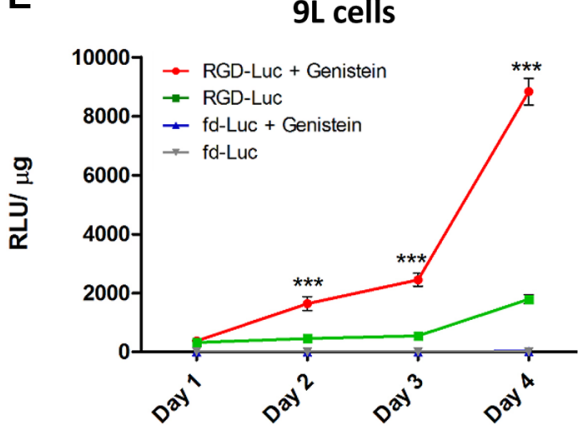

M21 cells

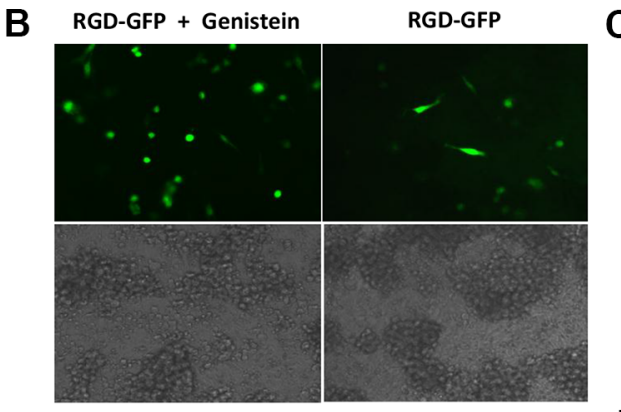

M21 cells

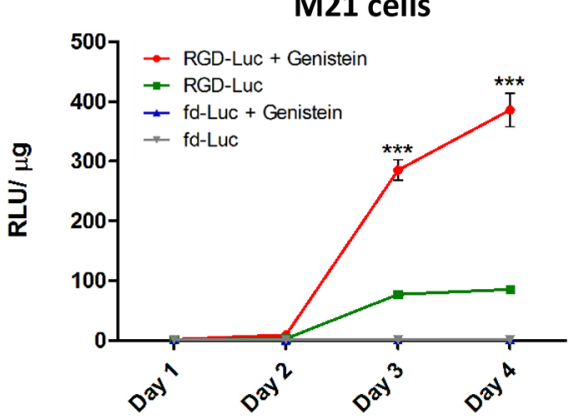

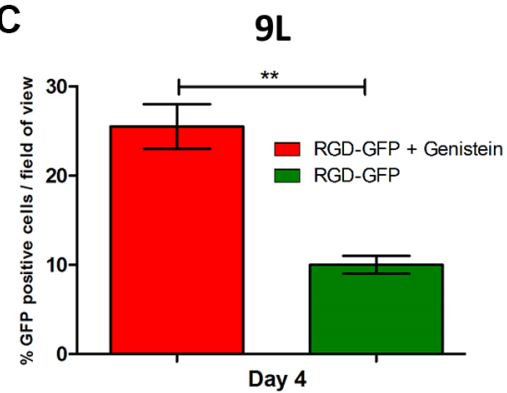

D

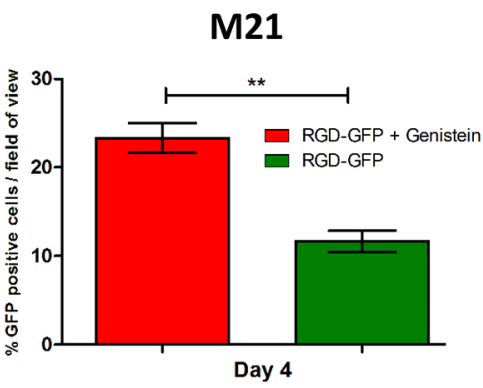

Figure 3: Genistein increased efficiency of gene transfer by AAVP in 9L and M21 tumor cells. 9L (A) and M21 cells (B) were plated on 48-well plates (70-80\% confluent) and transduced with RGD-GFP targeted or control non-targeted vectors in serum free medium for 4 hours with or without 2 hour pretreatment with genistein $(150 \mu \mathrm{M})$. GFP expression was monitored by fluorescent microscopy on day 4 post vector transduction, and also evaluated as average of GFP positive cells in five fields of view of 9L (C) and M21 (D) treated cells. 9L (E) and M21 cells (F) were plated on 48-well plates (70-80\% confluent) and transduced with targeted RGD-Luc or fdLuc control non-targeted vector in serum free medium for 4 hours with or without 2 hours pretreatment with genistein $(150 \mu \mathrm{M})$. Luciferase measurement assays were performed at day 1-4 post vector transduction and normalized to protein concentration as determined by the Bradford assay. Results are shown as RLU (Relative Luciferase Units) per $1 \mu \mathrm{g}$ of protein and represent the average from triplicate wells. The experiment was repeated twice in triplicate and the results shown are representative of one experiment. 
cell attachment and internalization of the RGD4C-AAVP viral particles.

\section{Genistein protects RGD4C-AAVP from proteasome degradation}

After ruling out the effect of genistein on vector cell entry, we sought to determine whether genistein improves intracellular persistence of the RGD4C-AAVP. We investigated the effect of genistein pretreatment of tumor cells on vector protection against proteasome degradation as we previously reported that proteasome is a barrier to gene transfer by RGD4C-AAVP vectors [12], and because genistein was found to possess proteasome-inhibitory activity [25]. 26S proteasome targets the degradation of polyubiquitinated protein substrates; thus inhibition of proteasome degradation by genistein would lead to accumulation of AAVP ubiquitination [32]. Therefore, we investigated whether genistein increases polyubiquitination of AAVP phage coat proteins. 9L tumor cells were transduced with RGD-Luc vector alone or following pretreatment with genistein. Next, the cells were analyzed for co-localization of AAVP coat proteins and ubiquitin by immunofluorescence as reported [33], by using antibodies against ubiquitin and
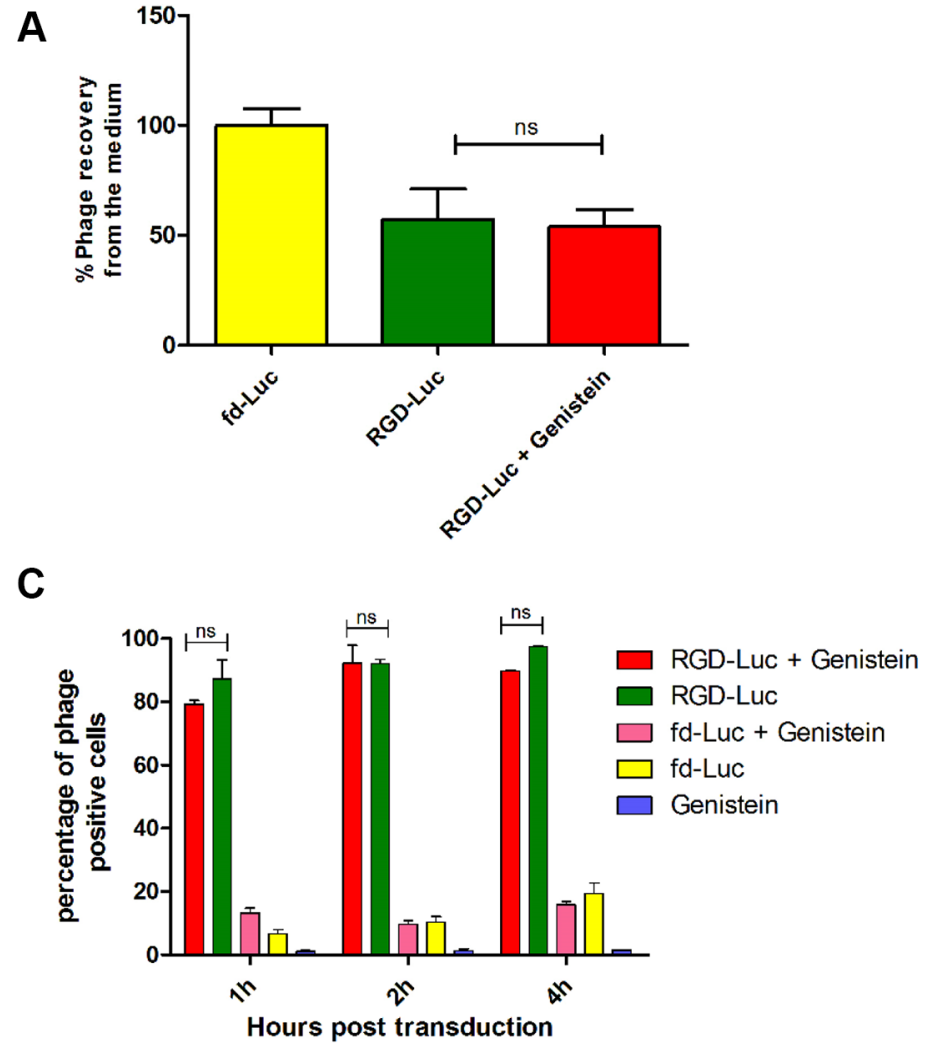

phage coat proteins (Figure 5). Confocal microscopic analysis showed strong co-localization of ubiquitin and AAVP coat proteins in cells treated with combination of vector and genistein (Figure 5). These data demonstrate that combination treatment results in accumulation of polyubiquitinated AAVP particles compared to treatment with the targeted vector alone, indicating that genistein can increase the gene transfer efficiency by inhibiting proteasome-mediated degradation of AAVP particles.

\section{Genistein enhances nuclear localisation of the RGD4C-AAVP vector genome}

Finally, we examined vector's genome accumulation in the nucleus to check whether enhanced resistance of vector to proteasome degradation would result in enhanced nuclear localisation of vector's genome. Additionally, genistein has been reported to induce G2/M cell cycle arrest, which results in pronounced opening of the nuclear pores allowing better nuclear transport of gene delivery vectors [26-28].Thus, we evaluated the nuclear accumulation of the AAV2 transgene cassette, since gene expression by RGD4C-AAVP is mediated through its AAV2 transgene cassette. 9L cells were

\section{B}

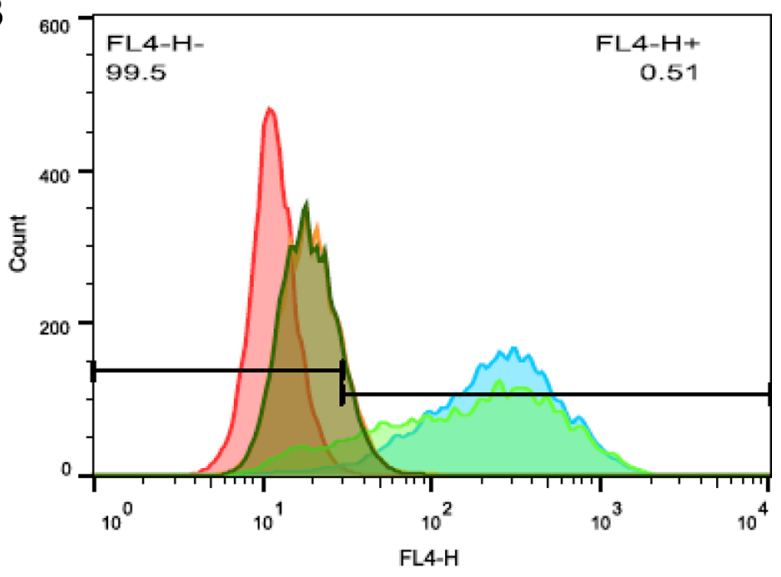

Figure 4: Analysis of cellular attachment and internalization of AAVP vector in combination with genistein. (A) Cellular attachment of RGD4C-GFP was evaluated by titrating the unbound phage in the supernatant of 9L cells following bacterial colony counting. The experiment was repeated twice in triplicate and the results shown are representative of one experiment. (B) Evaluation of vector internalization in the presence or absence of genistein. Graph showing FACS results after immunostaining of 9L cells treated with vectors in the presence or absence of genistein. (C) Graph showing the percentage of positive cells according to FACS data at three different time points (1, 2 and 4 hours) post incubation with vector. The experiment was carried out in triplicate. 
transduced with RGD-Luc or fd-Luc non-targeted vector with or without 2 hours pretreatment with genistein $(150 \mu \mathrm{M})$, and harvested at day 4 post transduction. Next, the nuclei were extracted from cells, followed by PCR using primers reading within the AAV2 ITR domain, as previously described [34], in order to semi-quantify the amount of vector genome in the nucleus (Figure 6). The data revealed a PCR product at the expected size, and electrophoresis gel analysis showed increased intensity of the ITR-derived PCR product when RGD-Luc vector was used in combination with genistein (Figure 6A). Then product quantification of the band intensities using Image software confirmed that combination of genistein with the targeted vector resulted in significant increase of vector DNA in the nucleus (Figure 6B).

\section{Evaluation of efficacy of genistein and RGD4C- AAVP combination in a three-dimensional (3D) multicellular tumor spheroid}

After showing that genistein dramatically increased RGD4C-AAVP mediated targeted killing of tumor cells in vitro, we set up to assess the efficacy of this combination in 3D tumor spheroids that simulate the
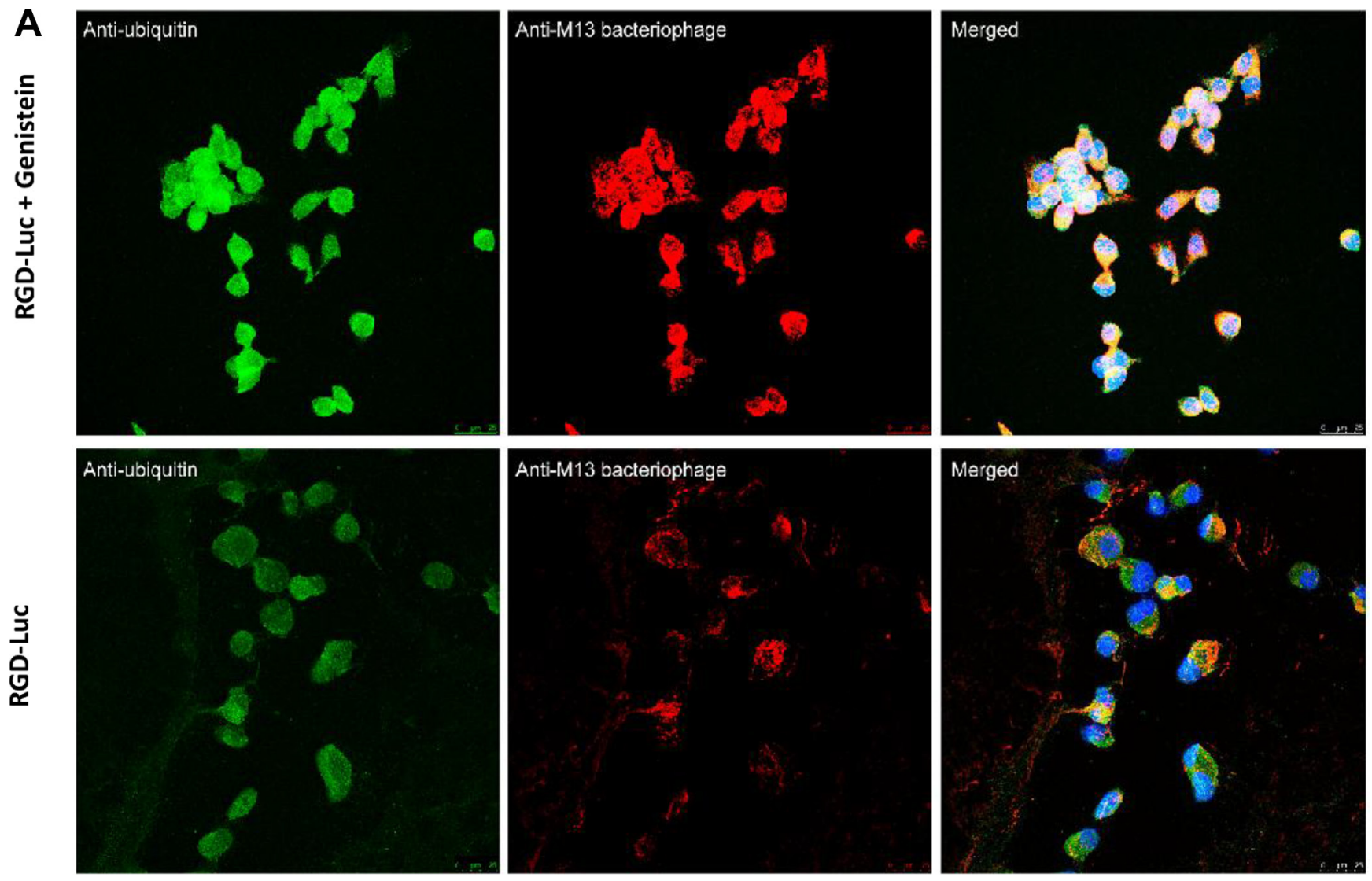

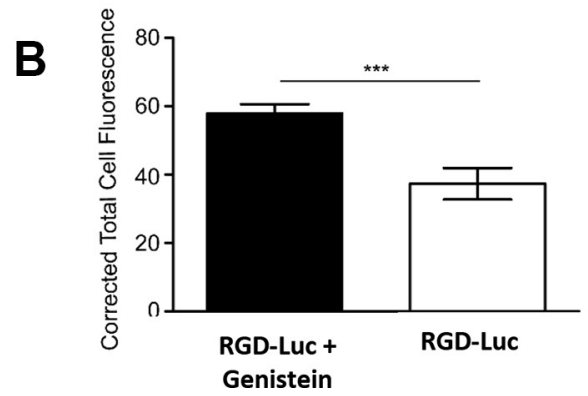

Figure 5: Polyubiquitination of RGD4C-AAVP particle is increased by genistein. (A) 9L cells were transduced by targeted AAVP (RGD-Luc) in serum-free medium for 4 hours with or without pretreatment with genistein $(150 \mu \mathrm{M}) .6$ hours post transduction, RGD-Luc was detected using rabbit anti-M13-phage primary and goat anti-rabbit AlexaFluor-647 secondary antibodies (shown in red) and ubiquitin was stained using mouse anti-ubiquitin primary and AlexaFluor-488 secondary antibodies (shown in green). Samples were analyzed by confocal microscopy and representative sections are shown. (B) Corrective total cell fluorescence analysis of ubiquitination in single optical sections using ImageJ. Data represent the mean \pm standard error of the mean (s.e.m.) of five independent optical sections. 
3D tumors more accurately. The 3D tumor spheroids are considered valid models to recapitulate features of solid tumors and were used in this study to evaluate and confirm the efficacy of gene therapy by the targeted RGD4CAAVP in combination with genistein. Since the increased tumor cell killing in vitro of the combination genistein and RGD4C-AAVP was associated with the enhancing effect of genistein on RGD4C-AAVP-mediated gene transfer, we first assessed the efficacy of gene transfer using vector carrying the GFP reporter gene to allow microscopic imaging of GFP expression within the 3D models of 9L and M21 tumor spheroids (Figure 7). The 9L and M21 tumor spheroids were transduced with targeted RGDGFP or control non-targeted fd-GFP with or without pretreatment with genistein $(150 \mu \mathrm{M})$. GFP expression was monitored with fluorescent microscopy over a period of 10 days to allow detectable gene expression by the RGD-GFP in the spheroids. While the targeted RGD-GFP showed minimal GFP expression in the spheroids at day 10 post transduction, combination treatment (RGD-GFP + Genistein) yielded dramatic increase in GFP expression compared to RGD-GFP treatment alone in both 9L and M21 spheroids (Figure 7).

Next, application of $H S V t k / G C V$ suicide gene therapy on rat 9L and human M21 tumors in vitro resulted in regression of the 9L and M21 spheroid volumes by combination of genistein with the targeted RGD-HSVtk upon GCV treatment, compared to individual treatments with RGD-HSVtk or genistein alone (Figure $8 \mathrm{~A}$ and $8 \mathrm{~B}$ ). Subsequently, measurement of cell viability in $9 \mathrm{~L}$ spheroids showed that combination of genistein plus RGDHSVtk achieved higher tumor cell killing $\sim 93 \%$, than the targeted RGD-HSVtk or genistein alone that induced $\sim 81 \%$ and $\sim 33 \%$ cancer cell killing, respectively (Figure $8 \mathrm{C}$ ). In M21 spheroids, measurement of cell viability showed that combination of genistein plus RGD4C-HSVtk achieved higher tumor cell killing $\sim 65 \%$ than the targeted RGDHSVtk or genistein alone that induced $\sim 33 \%$ and $\sim 24 \%$ cancer cell killing, respectively (Figure 8D). These findings clearly establish that combination of genistein with RGD4C-AAVP-mediated gene therapy greatly increases its potential as a gene therapy vector.

\section{DISCUSSION}

We have demonstrated that genistein pretreatment of tumor cells from different histopathological types and species resulted in enhanced targeted tumor cell killing by RGD4C-AAVP-mediated HSVtk and GCV suicide gene therapy in 2D tissue culture and 3D tumor spheroid settings. Then, we found that treatment with genistein of 9L and M21 cancer cells increased GFP and Luc reporter gene expression, which demonstrates that the enhanced tumor cell killing of RGD4C-AAVP by genistein is associated with increased HSVtk gene expression. Moreover, we have investigated the mechanisms linked with this increased reporter gene expression and tumor cell killing. Importantly gene transfer by RGD4C-AAVP remains targeted in the presence of genistein, indicating that the tumor specificity of RGD4C-AAVP is not affected

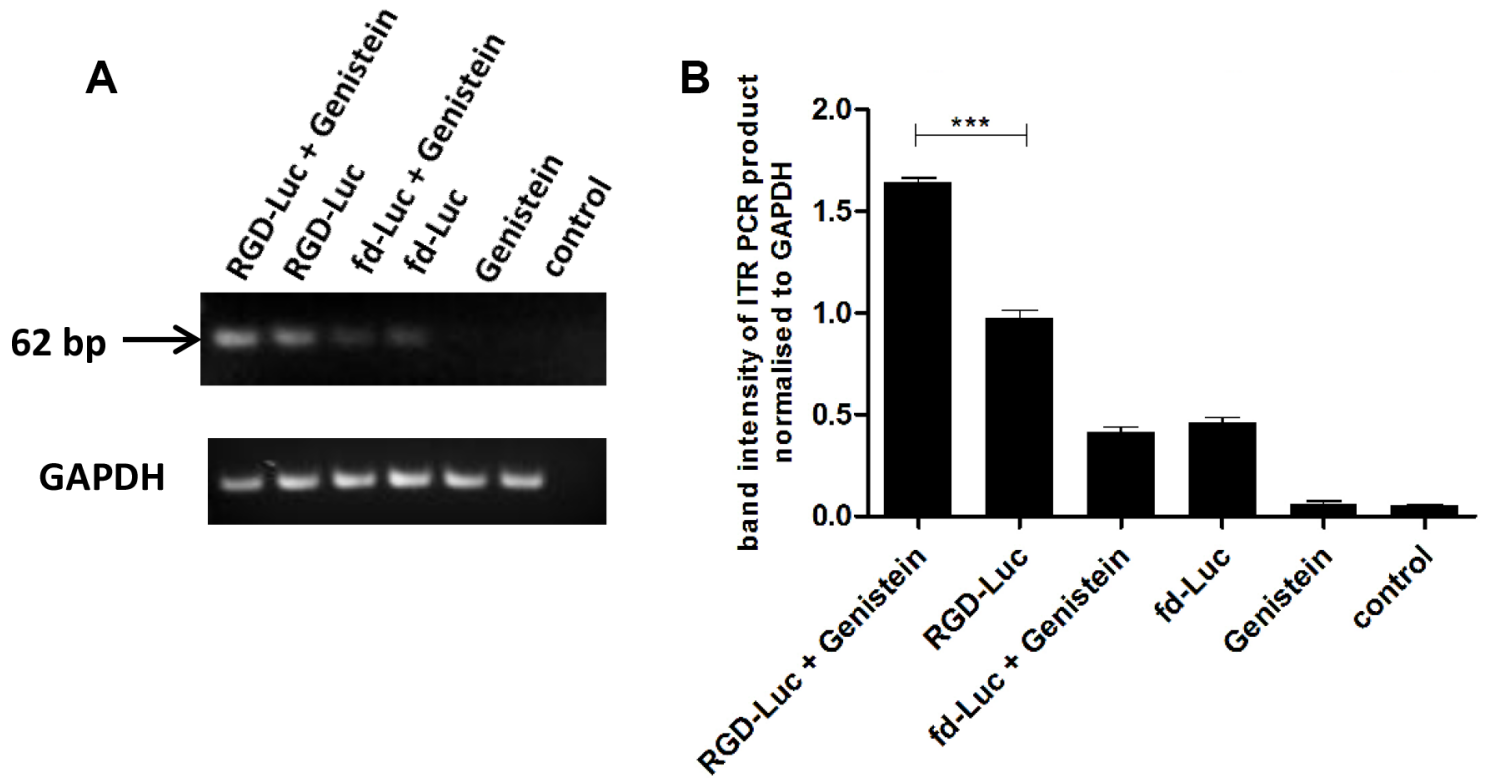

Figure 6: Genistein enhances AAVP vector genome accumulation in the nucleus. (A) 9L cells were plated on 48-well plates (70-80\% confluent) and transduced with targeted RGD-Luc or fd-Luc control non-targeted vector in serum free medium for 4 hours with or without 2 hours pretreatment with genistein $(150 \mu \mathrm{M})$. On day 4 after transduction, cells were harvested and nuclei extracted. Subsequently, DNA was extracted and used as template (10 ng of DNA) for PCR of the ITR domain in order to semi-quantify the amount of vector in the nucleus with or without pretreatment with genistein. Similar amount of DNA (10 ng) was used as template for PCR of the GAPDH gene. The experiment was carried out in triplicate. (B) The band intensity of the ITR PCR product was quantified using ImageJ software and normalized to GAPDH. PCR of the ITR domain was repeated three times and shown is the average. 
by genistein. We also found that genistein increases polyubiquitination of AAVP particles and accumulation of vector genome in the nucleus. These data suggest that genistein may bestow an advantage in gene expression from RGD4C-AAVP by means of increased vector accumulation in the nucleus and vector protection from proteasome degradation, or perhaps a combination of these two non-mutually exclusive mechanisms.

Our findings of increased RGD4C-AAVP-mediated cancer gene therapy are in agreement with a previous report showing enhanced cancer cell killing by a mutant oncolytic adenovirus in combination with genistein [35]. The observed difference in cell viability between 9L and M21 cell lines can be attributed partially to the fact that 9L cells can get transduced more easily compared to M21 cells and also to the bystander effect of the HSVtk/GCV in 9L cells [36]. The enhanced RGD4C-AAVP-mediated GFP and $L u c$ gene expression by genistein is also consistent with previous reports that genistein increased AAV2-mediated gene transfer in the human HeLa cervical carcinoma cells [23]. Moreover, the authors reported that genistein enhanced accumulation of the dephosphorylated form of single-stranded D-sequence-binding protein (ssD$\mathrm{BP}$ ), which facilitates the conversion of single to double stranded DNA resulting in improved AAV gene expression [23]. Importantly, our findings that genistein increased AAV2 PCR product in the nuclear fraction of cells treated with RGD4C-AAVP are consistent with that study, as gene expression by RGD4C-AAVP is mediated by the AAV2 transgene cassette, incorporated within the phage genome. The increased nuclear accumulation of AAVP genome, upon genistein pre-treatment, provides an additional mechanism that could further explain the improved AAVPmediated gene expression by genistein. One explanation is that pretreatment with genistein enhances the size of the nuclear pores, as genistein was reported to induce G2/M cell cycle arrest, during which nuclear localisation of gene therapy vectors can be enhanced [26-28].

Moreover, resistance to proteasome degradation upon genistein pretreatment should result in better intracellular persistence and availability of the RGD4CAAVP particles to be transported to the nucleus. These data also suggest that genistein increases the RGD4CAAVP-targeted gene expression, at least in part, through inhibition of proteasome-mediated degradation of the RGD4C-AAVP particles. Indeed, genistein was reported to inhibit the chymotrypsin-like activity of proteasome in purified $20 \mathrm{~S}$ proteasome and $26 \mathrm{~S}$ proteasome [25]. Also,

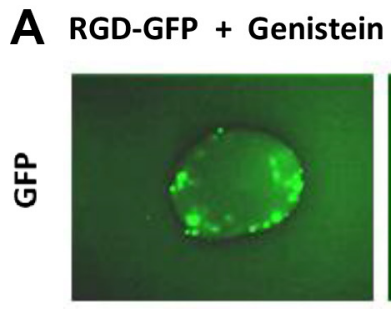

RGD-GFP
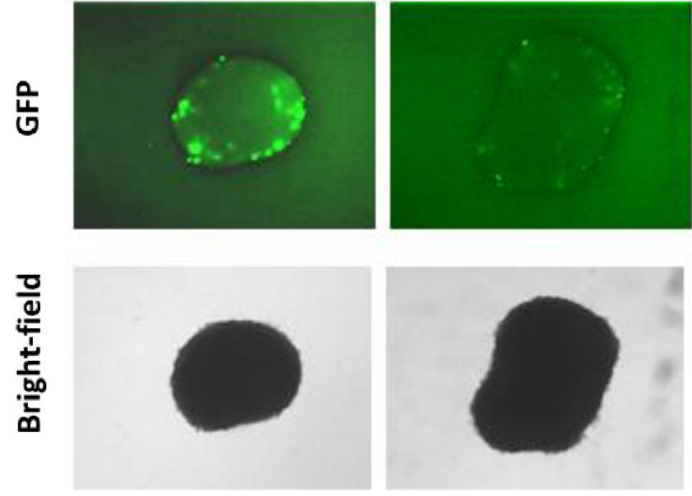

B
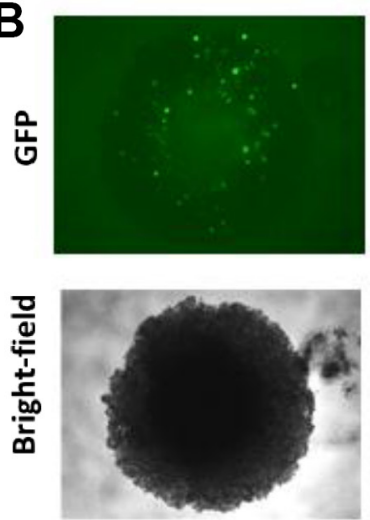
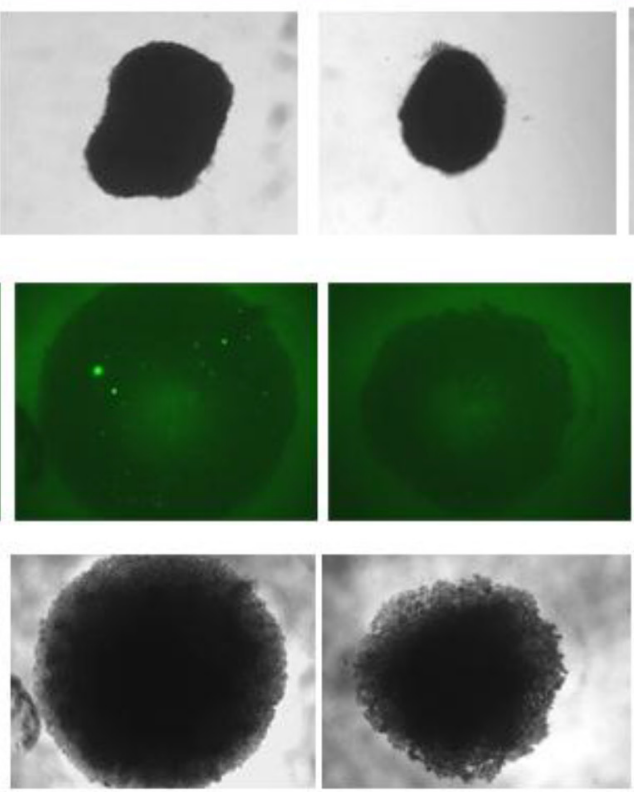

fd-GFP + Genistein
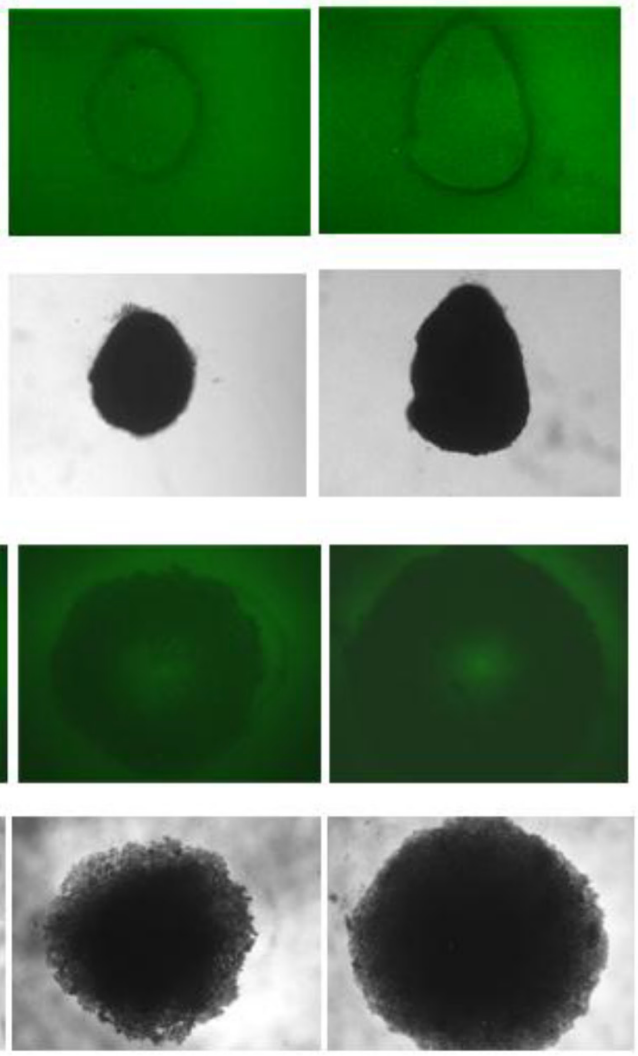

Figure 7: Genistein increased RGD4C-AAVP-mediated gene transfer in 9L and M21 tumor spheroids. 9L (A) and M21 (B) cells $\left(5 \times 10^{3}\right)$ were seeded into a 96-well ultra-low attachment surface plate in $200 \mu \mathrm{L}$ complete medium. After 48 hours of incubation, a spheroid was formed in each well. Spheroids were then transduced with RGD-GFP or control fd-GFP non-targeted vector with or without pretreatment with genistein $(150 \mu \mathrm{M})$. GFP expression was evaluated with fluorescent microscopy at day 10 post vector transduction. 
this is in agreement with our previous report showing that the proteasome inhibitors MG132 and LLnL increased persistence of RGD4C-AAVP particles in cancer cells in vitro and in tumors in vivo and subsequently improved gene expression from the vector both in vitro and in vivo [12]. MG132 and LLnL are peptide aldehyde inhibitors that reversibly inhibit the $26 \mathrm{~S}$ proteasome activity and most widely used in proteasome inhibition studies. The clinically used proteasome inhibitors bortezomib and carfilzomib, in patients with myeloma and other haematological malignancies, were reported to increase transduction efficiency of AAV vectors in hepatic cells and HeLa cell line $[37,38]$. However, bortezomib and carfilzomib did not show any enhancing effect on the transduction efficiency of RGD4C-AAVP in 9L and M21 cancer cell lines, although using various doses (Supplementary Figures 3 and 4). Compared to MG132 and LLnL, bortezomib and carfilzomib are stronger proteasome inhibitors even when used at low doses, which could result in increased cancer cell distress and subsequent reduction of RGD4C-AAVP gene expression.

Taking into account that genistein doesn't affect vector attachment on the surface of cancer cells nor its internalisation (Figure 4), our data indicate that genistein affects the intracellular fate of AAVP. It is important to note that other mechanisms of action of genistein might also

A
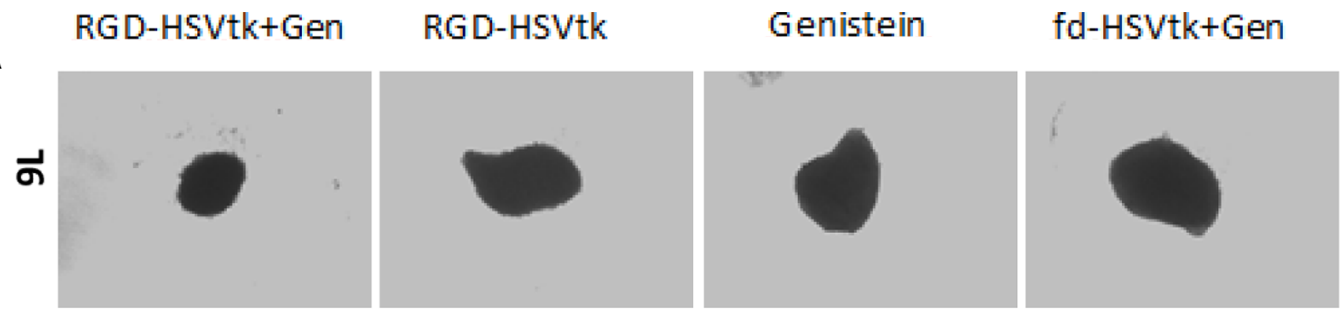

fd-HSVtk

B

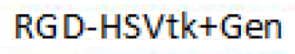

RGD-HSVtk

Genistein

fd-HSVtk+Gen
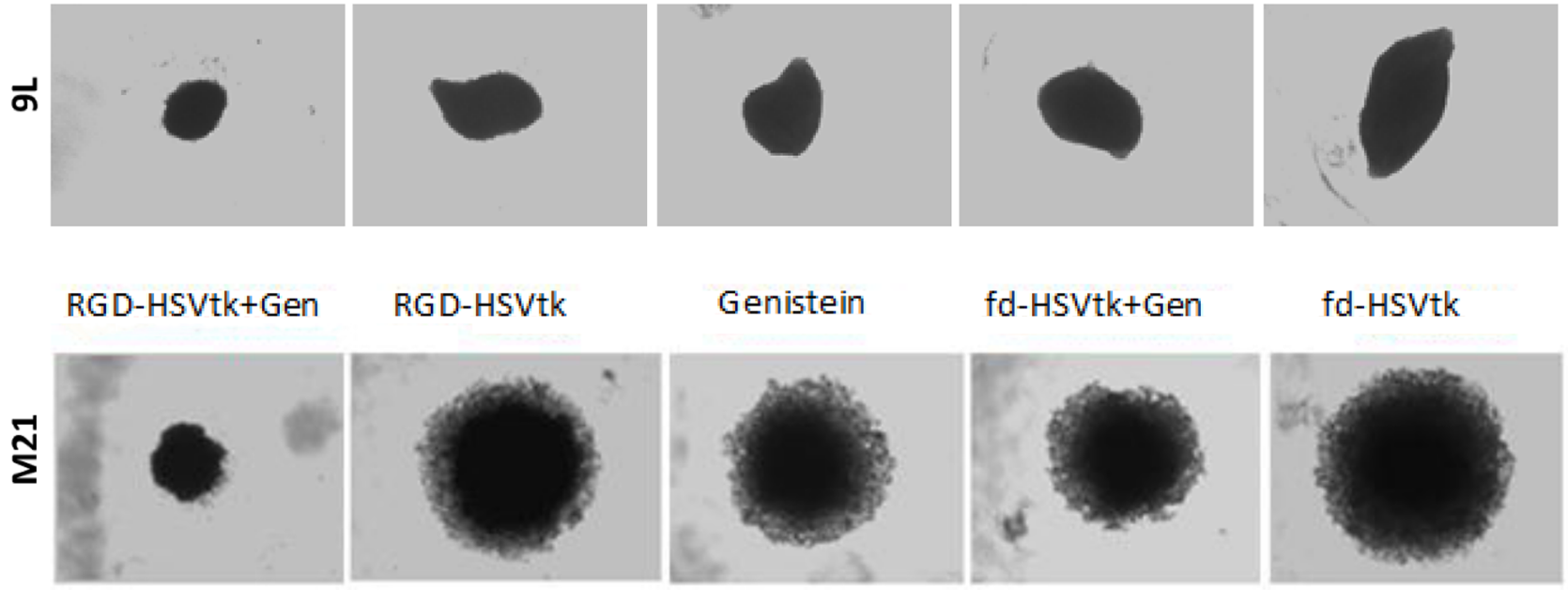

fd-HSVtk

C

9L cells

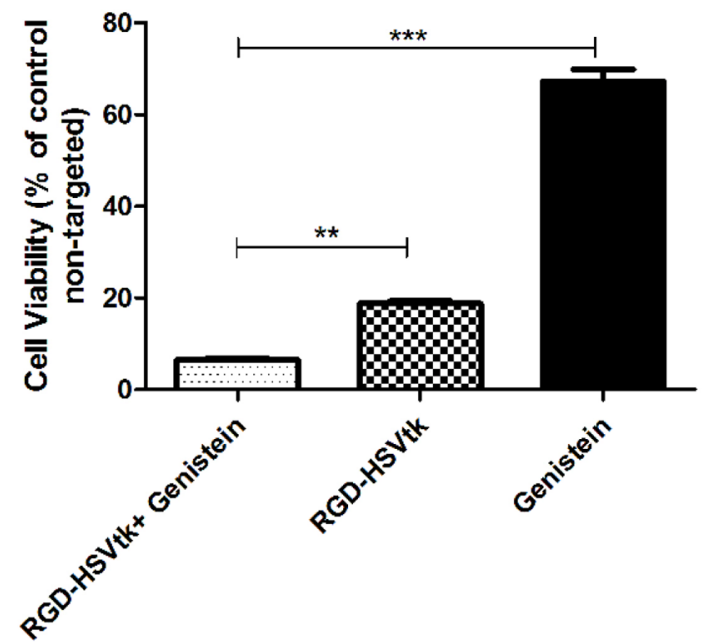

D

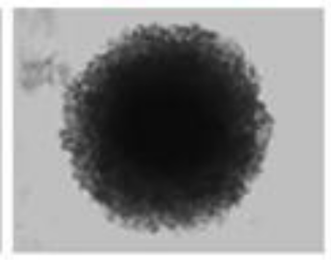

M21 cells

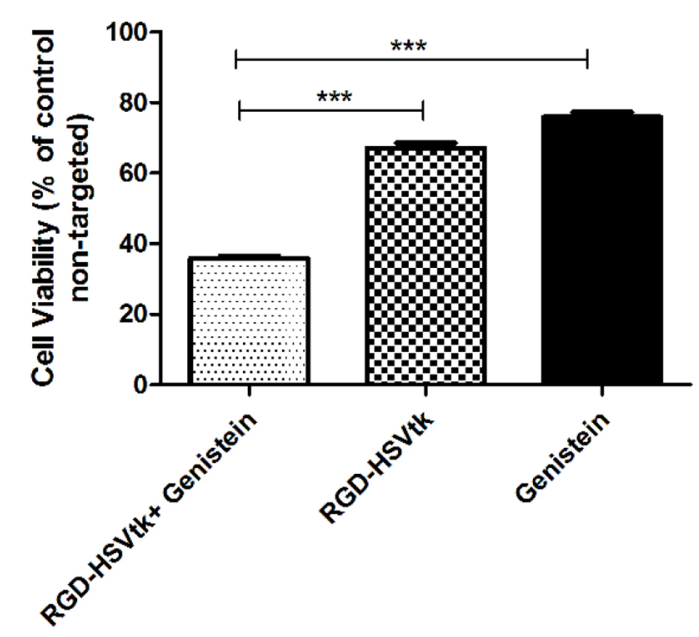

Figure 8: Antitumor efficacy of RGD4C-AAVP in combination with genistein in 3D tumor spheroid models. Bright-field images showing the size of 9L (A) and M21 (B) spheroids following transduction with RGD-HSVtk or fd-HSVtk non-targeted vector with or without pretreatment with genistein $(150 \mu \mathrm{M})$. GCV was added to the spheroids at day 5 post vector transduction and renewed every 2 days. Images were taken at day 5 or day 7 post GCV treatment for 9L and M21 spheroids, respectively. (C) Evaluation of cell viability in 9L spheroids at day 5 post GCV treatment. (D) Evaluation of cell viability in M21 spheroids at day 7 post GCV treatment. Cell viability was assessed by using the Cell Titer-Glo cell viability assay. The experiments were repeated twice in triplicate and the results shown are representative of one experiment. 
account for its enhancing effect on transduction efficiency of RGD4C-AAVP. For instance, genistein was reported to modulate the lysosomal metabolism [39]. Given that the endosomal-lysosomal pathway has been identified as an intracellular barrier to efficient transduction by RGD4C-AAVP [11], lysosomal alteration by genistein might facilitate RGD4C-AAVP escape from the lysosomes and subsequently higher nuclear accumulation of AAVP genome and enhanced gene expression.

In conclusion, despite their advantageous natural characteristics, bacteriophage viruses are still considered poor vectors for gene delivery due to their low gene transfer efficiency compared to eukaryotic vectors. The AAVP vector was reported as an improved version of phage-based gene therapy vectors to achieve enhanced gene delivery compared to conventional phage-derived vectors. Although promising, AAVP still has limitations inherent to bacteriophage. In this study we have shown that combining targeted RGD4C-AAVP with genistein significantly improves AVVP-guided gene transfer efficacy and consequently its cancer cell killing as a gene therapy vector. In addition, we elucidated possible mechanisms of increased AAVP-mediated gene expression by genistein. The next preclinical step will be taken to assess efficacy of this combination treatment in tumor-bearing mice. Given that genistein and AAVP have been demonstrated to cross the blood-brain barrier $[40,41]$, this combination treatment has potential applications for brain tumors. Our study indicates that combination of RGD4C-AAVP and genistein, is a promising strategy that can be considered for future clinical applications of targeted systemic gene therapy with RGD4C-AAVP in cancer patients.

\section{MATERIALS AND METHODS}

\section{Cells and reagents}

The rat 9L glioblastoma cells were a gift from Dr Hrvoje Miletic (University of Bergen, Norway), while the human M21 melanoma cells were from the American Type Culture Collection (ATCC). Both cell lines were maintained in a humidified incubator at $37^{\circ} \mathrm{C}$ in $5 \% \mathrm{CO}_{2}$ and cultured in Dulbecco's Modified Eagle's Medium (Sigma) supplemented 10\% fetal bovine serum (FBS, Sigma), penicillin (100 units $/ \mathrm{ml}$, Sigma), streptomycin $(100 \mu \mathrm{g} / \mathrm{ml}$, Sigma), and L-glutamine (2 mmol/l, Sigma). Genistein was purchased from Sigma and a stock solution $(150 \mathrm{mM})$ was prepared in dimethyl sulfoxide (DMSO, Sigma).

\section{MTT [3-(4,5-Dimethylthiazol-2-yl)-2,5- Diphenyltetrazolium Bromide] assay}

Cytotoxicity of genistein was assessed by using the MTT assay (colorimetric assay to measure cell viability based on mitochondrial activity, Sigma). 9L and M21 cells were plated in 96-well plates at a density of $4 \times 10^{3}$ cells per well. Next day, complete medium $(100 \mu \mathrm{l})$ containing different concentrations of genistein were added to cells in triplicates. After 2 hours treatment, the genisteincontaining medium was removed and replaced with $100 \mu \mathrm{l}$ fresh medium. MTT assay was carried out after 48 hours.

\section{Production, purification and titration of AAVP vectors}

AAVP vectors were generated as previously reported [7] by inserting the mammalian cassette from AAV2 containing the reporter or therapeutic genes into the fUSE5 plasmid derived from the filamentous fd-tet bacteriophage. AAVP viral particles were produced and purified from the culture supernatant of Escherichia Coli K91 host bacteria as previously described [7], then sterilefiltered through $0.45 \mu \mathrm{M}$ filters. The titration was carried out by preparing serial dilutions of the AAVP and infecting K91 host bacteria, which subsequently form colonies when plated on selective Luria-Bertani agar. The AAVP titre is calculated by counting the number of colonies multiplied by the dilution of the AAVP and is expressed as bacterial transducing units $(\mathrm{TU} / \mu \mathrm{l})$ as previously described [7].

\section{In vitro cell transduction by AAVP vectors}

9L and M21 cells were counted, then plated on 48-well plates and grown for 48 hours until they reach $70-80 \%$ confluence. Genistein was diluted in complete medium and added to the cells (as indicated) at a final concentration of $150 \mu \mathrm{M}$ [24]. After 2 hours treatment, genistein-containing medium was removed and cells were washed with serum-free medium. Subsequently, cells were incubated with targeted RGD4C-AAVP or control nontargeted AAVP vectors $\left(10^{6} \mathrm{TU} /\right.$ cell for $H S V t k$ carrying vectors, $2.5 \times 10^{5} \mathrm{TU} /$ cell for GFP carrying vectors, and $10^{4} \mathrm{TU} /$ cell for Luc carrying vectors) in serum-free medium $\left(150 \mu \mathrm{l}\right.$ total volume per well) at $37^{\circ} \mathrm{C}$ in the $\mathrm{CO}_{2}$ incubator for 4 hours and manually rotated every $30 \mathrm{~min}$ during incubation. After 4 hours, $350 \mu$ of complete medium were added to make the total volume up to $500 \mu \mathrm{l}$ per well. Cell transduction efficacy in vitro was evaluated by using the green fluorescent protein $(G F P)$ and the firefly luciferase $(L u c)$ reporter genes. The variation in the TU/cell amounts used between vectors carrying different transgenes is related to the sensitivity of the assay. For instance, given the sensitivity of the luciferase assay, we used $10^{4} \mathrm{TU} /$ cell to avoid saturation of the signal.

\section{Reporter gene assays}

Quantification of luciferase expression was carried out by using the Steady-Glo luciferase assay (Promega). Medium was removed and $110 \mu$ of Glo Lysis buffer, was added per well of 48 well plate. After 10 min incubation, $50 \mu \mathrm{l}$ of the cell lysate was transferred to a 96-well white opaque microplate (BD, Falcon) and mixed with an equal volume of Steady-Glo ${ }^{\circledR}$ luciferase substrate (Promega). 
After 10 min the plate was read using a Promega Glomax plate reader. Luciferase expression was normalized to $100 \mu \mathrm{g}$ protein levels from cell lysates as determined by the Bradford assay (Sigma). Results are shown as Relative Luciferase Units (RLU) per $100 \mu \mathrm{g}$ of protein. GFP expression was visualized using a Nikon Eclipse TE2000-U fluorescence microscope.

\section{Determination of tumor cell killing in vitro}

9L and M21 cells were seeded in 48 well-plates for 48 hours until they reach $70-80 \%$ confluence. Then, cells were transduced with RGD4C-AAVP or control nontargeted vector carrying thymidine kinase of the herpes simplex virus type 1 (RGD-HSVtk) gene with or without 2 hours pretreatment with genistein $(150 \mu \mathrm{M})$. Ganciclovir (GCV, Sigma) was added to the cells $(20 \mu \mathrm{M})$ at day 3 post vector transduction and renewed daily. Cancer cell killing was quantified at $0,24,48,72,96$ hours post GCV treatment. Cells were counted by using the trypan blue exclusion methodology. Results were normalized to nontargeted vector (fd-HSVtk).

\section{D model of multicellular tumor spheroid culture and treatment}

9L and M21 multicellular tumor spheroids were prepared by seeding $5 \times 10^{3}$ cells into a 96-well ultra-low attachment surface plate (Corning) in $200 \mu \mathrm{L}$ complete medium. After 48 hours of incubation, a spheroid was formed in each well. Then, after removing $100 \mu$ l of media, spheroids were incubated with targeted vectors or control non-targeted vectors in $100 \mu \mathrm{l}$ complete medium with or without 2 hours pre-treatment with genistein $(150 \mu \mathrm{M})$. 24 hours later, the medium was replaced with $200 \mu \mathrm{l}$ complete medium and renewed every 3 days by fresh complete medium. GFP gene expression was evaluated using fluorescent microscopy at day 10 post transduction. When spheroids were transduced with vectors carrying the HSVtk gene, GCV $(20 \mu \mathrm{M})$ were added on day 5 post vector transduction and renewed every 2-3 days. Cell viability in the spheroids was evaluated post GCV treatment by using CellTiter-Glo assay (Promega). First, medium was removed and then $100 \mu \mathrm{l}$ of Glo Lysis buffer, $1 \mathrm{x}$, were added in each well. After $30 \mathrm{~min}$ incubation, the spheroids were dissolved by pipetting in the lysis buffer or using a sonicator. $50 \mu \mathrm{l}$ of the lysate was then transferred to a 96-well white opaque microplate (BD Falcon), mixed with an equal volume of CellTiter-Glo substrate (Promega) and read with a Promega Glomax plate reader.

\section{Nuclei extraction}

9L cells were plated on 48-well plates (70-80\% confluent) and transduced with RGD4C-AAVP carrying the Luc gene (RGD-Luc) or control non-targeted fd-Luc vectors in serum-free medium for 4 hours with or without 2 hours pretreatment with genistein $(150 \mu \mathrm{M})$. On day 4 after transduction, cells were harvested and nuclei were extracted as previously reported [42]. Cells were washed with phosphate buffered saline (PBS, Sigma), trypsinized and then pelleted by centrifugation at $1500 \times \mathrm{g}$ for $5 \mathrm{~min}$. The pellet was washed with PBS and pelleted again by centrifugation at $1500 \times \mathrm{g}$ for $5 \mathrm{~min}$. Subsequently, the pellet was resuspended in hypotonic buffer $(20 \mathrm{mM}$ Hepes-KOH, pH 8.0, 5 mM KCl, 1.5 mM MgCl2, 5 mM Sodiumbutyrate, $0.1 \mathrm{mM}$ dithiothreitol [DTT]) and lysed by dounce homogenization. Nuclei were collected by centrifugation $\left(10 \mathrm{~min}, 16,000 \times \mathrm{g}, 4^{\circ} \mathrm{C}\right)$ and resuspended in nuclear extraction buffer $(15 \mathrm{mM}$ Tris- $\mathrm{HCl}, \mathrm{pH} 7.5$, $1 \mathrm{mM}$ EDTA, $0.4 \mathrm{M} \mathrm{NaCl}, 10 \%$ sucrose, $1 \mathrm{mM}$ DTT). DNA was extracted using Phenol/Chloroform/Isoamyl alcohol mixture (Sigma) and precipitated by $100 \%$ ethanol (Sigma). The precipitates were washed with $80 \%$ ethanol and resuspended in $10 \mathrm{mM}$ Tris- $\mathrm{HCl}, \mathrm{pH} 8.5$.

\section{Semi-quantitative polymerase chain reaction (PCR) analysis}

After extraction, DNA was used as a template for PCR targeting the ITR domain of the vector in order to semi-quantify the amount of vector in the nucleus with or without pretreatment with genistein. The same amount of DNA was used as template for PCR of the GAPDH gene. PCRs were performed in a $25 \mu \mathrm{l}$ volume containing $2 \mathrm{mM} \mathrm{MgCl}, 0.4 \mathrm{mM}$ dNTP mixture (Invitrogen), $0.2 \mu \mathrm{M}$ forward ITR primer (fwd ITR primer, 5'-GGAACCCCTAGTGATGGAGTT-3'), $0.2 \mu \mathrm{M}$ reverse ITR primer (rev ITR primer, 5'-CGGCCTCAGTGAGCGA-3'), 10 ng DNA template and 1 Unit of Q5 polymerase (New England Biolabs). The PCR program contained an initial denaturation step at $98^{\circ} \mathrm{C}$ for $10 \mathrm{~min}$ followed by 35 cycles of denaturation at $98^{\circ} \mathrm{C}$ for $15 \mathrm{sec}$, annealing at $61.5^{\circ} \mathrm{C}$ for $30 \mathrm{sec}$, and extension at $72^{\circ} \mathrm{C}$ for $1 \mathrm{~min}$, with a final extension after the last cycle at $72^{\circ} \mathrm{C}$ for $5 \mathrm{~min}$ [34]. The 62-bp PCR product was analyzed on a $4 \%$ agarose gel. The band intensity of the PCR product was quantified using ImageJ software and normalized to GAPDH PCR product (Fwd gapdh primer: 5'-ATGAATACGGCTACAGCAACAGG-3', Rev gapdh primer: 5'-CTCTTGCTCAGTGTCCTTGCTG-3').

\section{Attachment assay}

9L and M21 cells were seeded in 48-well plates and grown for 48 hours until they reach $70-80 \%$ confluence. Genistein was diluted in complete medium and added to the cells (as indicated) at a final concentration of $150 \mu \mathrm{M}$ [24]. After 2 hours treatment, genistein-containing medium was removed and cells were treated with targeted or control non-targeted AAVP vectors $\left(10^{6} \mathrm{TU} /\right.$ cell $)$ in serum free medium $(150 \mu$ l total volume per well). The plates 
were placed on ice for 1 hour to prevent internalization of AAVP. Next, the supernatants were collected and serially diluted in PBS. The amount of AAVP particles in the supernatant was quantified using the K91 bacterial infection method, as previously described [7].

\section{Internalization assay}

Internalization assay was performed as previously described [10]. After 2 hours treatment with medium containing genistein $(150 \mu \mathrm{M})$, cells were incubated with targeted and control non-targeted vectors carrying the Luc gene $\left(10^{4} \mathrm{TU} /\right.$ cell $)$ in serum-free medium for 1 , 2 and 4 hours at $37^{\circ} \mathrm{C}$. Then, cells were cooled on ice to stop endocytosis and washed 3 times with PBS to remove unbound vectors. Cells were trypsinized for $5 \mathrm{~min}$ at $37^{\circ} \mathrm{C}$ (to remove surface-bound phage) and pelleted by centrifugation at $2000 \mathrm{rpm}$ for $5 \mathrm{~min}$. Subsequently, cells were fixed in 4\% paraformaldehyde (PFA, pH 7.2, Sigma) for 10 minutes at room temperature. Untreated cells were used as negative controls. Cells were blocked with $0.1 \%$ saponin in $2 \%$ bovine serum albumin in PBS (BSA-PBS) for $30 \mathrm{~min}$. To detect internalized phage-derived vectors, cells were stained with a polyclonal rabbit anti-M13bacteriophage antibody $(1: 1000$, Sigma) in $0.1 \%$ saponin in $1 \%$ BSA-PBS for $1 \mathrm{hr}$ at room temperature. Cells were washed three times (pelleted and resuspended) in $0.1 \%$ saponin in $1 \%$ BSA-PBS. Subsequently, cells were incubated with the secondary antibody, goat anti-rabbit AlexaFluor-647 (dilution 1:500, Life Technologies) for 1 hour at room temperature. Finally, cells were washed twice with $0.1 \%$ saponin-PBS and resuspended in PBS before analysis.

Fluorescence-activated cell sorting (FACS) analysis was carried out using a FACscalibur Flow cytometer (BD Biosciences). The mean fluorescence intensity was measured for at least 10,000 gated cells per triplicate well. Results were analyzed using Flowjo (TreeStar) software.

\section{Immunofluorescence staining}

9L cells were seeded on $18 \mathrm{~mm}^{2}$ coverslips in 12 -well plates. After 48 hours, cells at approximately $80 \%$ confluent were incubated with RGD-Luc vector $\left(10^{6}\right.$ TU/cell) in serum-free medium with or without 2 hours pre-treatment with genistein $(150 \mu \mathrm{M})$. After 4 hours, $350 \mu$ of complete medium were added to make up a total volume of $500 \mu \mathrm{l}$ per well. After 2 hours ( 6 hours post transduction), cells were washed with PBS and fixed in PBS containing 4\% paraformaldehyde (Sigma). Cells were then incubated in $50 \mathrm{mM}$ Ammonium Chloride for $5 \mathrm{~min}$, permeabilized with $0.2 \%$ Triton X-100 (Sigma), washed, and blocked with PBS containing 2\% BSA. Subsequently, cells were incubated with a rabbit anti-M13 bacteriophage (1:1000, Sigma) and mouse anti-ubiquitin (1:200,
Invitrogen) diluted in $1 \% \mathrm{BSA}$ at $4^{\circ} \mathrm{C}$ overnight. Next day, cells were washed with PBS and incubated for 1 hour at room temperature with $1 \%$ BSA containing anti-rabbit and anti-mouse Alexa Fluor-conjugated secondary antibodies (1:750, Invitrogen) and also DAPI (1:2000, Sigma). Cells were washed three times in PBS and twice in distilled water, allowed to air-dry and mounted in Prolong Gold antifade reagent (Invitrogen). Images were acquired with a laser confocal microscope (Leica, Germany).

\section{Statistical analysis}

Statistical analysis was performed using GraphPad Prism software (version 5.0). Data are expressed as mean \pm standard error of the mean (s.e.m.). $P$ values were generated by one-way ANOVA and Tukey tests. $P$ values were considered significant when $<0.05$ and denoted as follows: $* p<0.05, * * p<0.01, * * * p<0.001$, n.s: nonsignificant.

\section{ACKNOWLEDGMENTS}

We thank Renata Pasqualini, Wadih Arap for reagents and Teerapong Yata for assistance. We also thank Glenda Gilles for editing and reading the manuscript.

\section{CONFLICTS OF INTEREST}

The authors have no conflicts of interest to declare.

\section{FUNDING}

This study was supported by a grant G0701159 of the UK Medical Research Council (MRC), the Brain Tumour Research Campaign (BTRC) and a Scholarship from the Onassis Foundation in Greece.

\section{REFERENCES}

1. Bosslet K, Straub R, Blumrich M, Czech J, Gerken M, Sperker B, Kroemer HK, Gesson JP, Koch M, Monneret C. Elucidation of the mechanism enabling tumor selective prodrug monotherapy. Cancer research. 1998; 58: 1195-1201.

2. Waehler R, Russell SJ, Curiel DT. Engineering targeted viral vectors for gene therapy. Nature reviews Genetics. 2007; 8:573-587.

3. Hajitou A, Trepel M, Lilley CE, Soghomonyan S, Alauddin MM, Marini FC, 3rd, Restel BH, Ozawa MG, Moya CA, Rangel R, Sun Y, Zaoui K, et al. A hybrid vector for ligand-directed tumor targeting and molecular imaging. Cell. 2006; 125:385-398.

4. Lang LH. FDA approves use of bacteriophages to be added to meat and poultry products. Gastroenterology. 2006; 131:1370. 
5. Greenstein D, Besmond C. Preparing and using M13derived vectors. Current protocols in molecular biology/ edited by Frederick M Ausubel [et al]. 2001; Chapter 1:Unit1 15 .

6. Chira S, Jackson CS, Oprea I, Ozturk F, Pepper MS, Diaconu I, Braicu C, Raduly LZ, Calin GA, BerindanNeagoe I. Progresses towards safe and efficient gene therapy vectors. Oncotarget. 2015; 6:30675-703. doi: 10.18632/oncotarget.5169.

7. Hajitou A, Rangel R, Trepel M, Soghomonyan S, Gelovani JG, Alauddin MM, Pasqualini R, Arap W. Design, construction of targeted AAVP vectors for mammalian cell transduction. Nature protocols. 2007; 2:523-531.

8. Hajitou A, Lev DC, Hannay JA, Korchin B, Staquicini FI, Soghomonyan S, Alauddin MM, Benjamin RS, Pollock RE, Gelovani JG, Pasqualini R, Arap W. A preclinical model for predicting drug response in soft-tissue sarcoma with targeted AAVP molecular imaging. Proceedings of the National Academy of Sciences of the United States of America. 2008; 105:4471-4476.

9. Paoloni MC, Tandle A, Mazcko C, Hanna E, Kachala S, Leblanc A, Newman S, Vail D, Henry C, Thamm D, Sorenmo K, Hajitou A, Pasqualini R, et al. Launching a novel preclinical infrastructure: comparative oncology trials consortium directed therapeutic targeting of TNFalpha to cancer vasculature. PloS one. 2009; 4:e4972.

10. Yata T, Lee KY, Dharakul T, Songsivilai S, Bismarck A, Mintz PJ, Hajitou A. Hybrid Nanomaterial Complexes for Advanced Phage-guided Gene Delivery. Molecular therapy Nucleic acids. 2014; 3:e185.

11. Stoneham CA, Hollinshead M, Hajitou A. Clathrinmediated endocytosis and subsequent endo-lysosomal trafficking of adeno-associated virus/phage. The Journal of biological chemistry. 2012; 287:35849-35859.

12. Przystal JM, Umukoro E, Stoneham CA, Yata T, O’Neill K, Syed N, Hajitou A. Proteasome inhibition in cancer is associated with enhanced tumor targeting by the adenoassociated virus/phage. Molecular oncology. 2013; 7:55-66.

13. Malvicini M, Aquino JB, Mazzolini G. Combined therapy for gastrointestinal carcinomas: exploiting synergies between gene therapy and classical chemo-radiotherapy. Current gene therapy. 2015; 15:151-160.

14. Conklin CM, Bechberger JF, MacFabe D, Guthrie N, Kurowska EM, Naus CC. Genistein and quercetin increase connexin43 and suppress growth of breast cancer cells. Carcinogenesis. 2007; 28:93-100.

15. Spagnuolo C, Russo GL, Orhan IE, Habtemariam S, Daglia M, Sureda A, Nabavi SF, Devi KP, Loizzo MR, Tundis R, Nabavi SM. Genistein and cancer: current status, challenges, and future directions. Advances in nutrition (Bethesda, Md). 2015; 6:408-419.

16. Xiao X, Liu Z, Wang R, Wang J, Zhang S, Cai X, Wu K, Bergan RC, Xu L, Fan D. Genistein suppresses FLT4 and inhibits human colorectal cancer metastasis. Oncotarget. 2015; 6:3225-3239. doi: 10.18632/oncotarget.3064.
17. Li CF, Wu WJ, Wu WR, Liao YJ, Chen LR, Huang CN, Li CC, Li WM, Huang HY, Chen YL, Liang SS, Chow NH, Shiue YL. The cAMP responsive element binding protein 1 transactivates epithelial membrane protein 2 , a potential tumor suppressor in the urinary bladder urothelial carcinoma. Oncotarget. 2015; 6:9220-9239. doi: 10.18632/ oncotarget.3312.

18. Banerjee S, Li Y, Wang Z, Sarkar FH. Multi-targeted therapy of cancer by genistein. Cancer letters. 2008; 269:226-242.

19. Shen M, Chan TH, Dou QP. Targeting tumor ubiquitin-proteasome pathway with polyphenols for chemosensitization. Anti-cancer agents in medicinal chemistry. 2012; 12:891-901.

20. Yang H, Zonder JA, Dou QP. Clinical development of novel proteasome inhibitors for cancer treatment. Expert opinion on investigational drugs. 2009; 18:957-971.

21. Jin CY, Park C, Kim GY, Lee SJ, Kim WJ, Choi YH. Genistein enhances TRAIL-induced apoptosis through inhibition of p38 MAPK signaling in human hepatocellular carcinoma Hep3B cells. Chemico-biological interactions. $2009 ; 180: 143-150$.

22. Zhou HB, Chen JJ, Wang WX, Cai JT, Du Q. Apoptosis of human primary gastric carcinoma cells induced by genistein. World journal of gastroenterology. 2004; 10:1822-1825.

23. Mah C, Qing K, Khuntirat B, Ponnazhagan S, Wang XS, Kube DM, Yoder MC, Srivastava A. Adeno-associated virus type 2-mediated gene transfer: role of epidermal growth factor receptor protein tyrosine kinase in transgene expression. Journal of virology. 1998; 72:9835-9843.

24. Qing K, Wang XS, Kube DM, Ponnazhagan S, Bajpai A, Srivastava A. Role of tyrosine phosphorylation of a cellular protein in adeno-associated virus 2-mediated transgene expression. Proceedings of the National Academy of Sciences of the United States of America. 1997; 94:10879-10884.

25. Kazi A, Daniel KG, Smith DM, Kumar NB, Dou QP. Inhibition of the proteasome activity, a novel mechanism associated with the tumor cell apoptosis-inducing ability of genistein. Biochemical pharmacology. 2003; 66:965-976.

26. Ouyang G, Yao L, Ruan K, Song G, Mao Y, Bao S. Genistein induces G2/M cell cycle arrest and apoptosis of human ovarian cancer cells via activation of DNA damage checkpoint pathways. Cell biology international. 2009; 33:1237-1244.

27. Cui S, Wienhoefer N, Bilitewski U. Genistein induces morphology change and $\mathrm{G} 2 / \mathrm{M}$ cell cycle arrest by inducing p38 MAPK activation in macrophages. International immunopharmacology. 2014; 18:142-150.

28. Han J, Kurita Y, Isoda H. Genistein-induced G2/M cell cycle arrest of human intestinal colon cancer Caco-2 cells is associated with Cyclin B1 and Chk2 down-regulation. Cytotechnology. 2013; 65:973-978.

29. Black ME, Kokoris MS, Sabo P. Herpes simplex virus-1 thymidine kinase mutants created by semi-random sequence 
mutagenesis improve prodrug-mediated tumor cell killing. Cancer research. 2001; 61:3022-3026.

30. Nishikawa M, Huang L. Nonviral vectors in the new millennium: delivery barriers in gene transfer. Human gene therapy. 2001; 12:861-870.

31. Wiethoff CM, Middaugh CR. Barriers to nonviral gene delivery. Journal of pharmaceutical sciences. 2003; 92:203-217.

32. Zhu Q, Wani G, Wang QE, El-mahdy M, Snapka RM, Wani AA. Deubiquitination by proteasome is coordinated with substrate translocation for proteolysis in vivo. Experimental cell research. 2005; 307:436-451.

33. Neumann M, Mackenzie IR, Cairns NJ, Boyer PJ, Markesbery WR, Smith CD, Taylor JP, Kretzschmar HA, Kimonis VE, Forman MS. TDP-43 in the ubiquitin pathology of frontotemporal dementia with VCP gene mutations. Journal of neuropathology and experimental neurology. 2007; 66:152-157.

34. Aurnhammer $C$, Haase $M$, Muether $N$, Hausl $M$, Rauschhuber C, Huber I, Nitschko H, Busch U, Sing A, Ehrhardt A, Baiker A. Universal real-time PCR for the detection and quantification of adeno-associated virus serotype 2-derived inverted terminal repeat sequences. Human gene therapy methods. 2012; 23:18-28.

35. Adam V, Ekblad M, Sweeney K, Muller H, Busch KH, Johnsen CT, Kang NR, Lemoine NR, Hallden G. Synergistic and Selective Cancer Cell Killing Mediated by the Oncolytic Adenoviral Mutant AdDeltaDelta and Dietary Phytochemicals in Prostate Cancer Models. Human gene therapy. 2012; 23:1003-1015.

36. Trepel M, Stoneham CA, Eleftherohorinou $H$, Mazarakis ND, Pasqualini R, Arap W, Hajitou A. A heterotypic bystander effect for tumor cell killing after adeno-associated virus/phage-mediated, vascular-targeted suicide gene transfer. Molecular cancer therapeutics. 2009; 8:2383-2391
37. Monahan PE, Lothrop CD, Sun J, Hirsch ML, Kafri T, Kantor B, Sarkar R, Tillson DM, Elia JR, Samulski RJ. Proteasome inhibitors enhance gene delivery by AAV virus vectors expressing large genomes in hemophilia mouse and dog models: a strategy for broad clinical application. Molecular therapy. 2010; 18:1907-1916.

38. Mitchell AM, Samulski RJ. Mechanistic insights into the enhancement of adeno-associated virus transduction by proteasome inhibitors. Journal of virology. 2013; 87 : 13035-13041.

39. Moskot M, Montefusco S, Jakobkiewicz-Banecka J, Mozolewski P, Wegrzyn A, Di Bernardo D, Wegrzyn G, Medina DL, Ballabio A, Gabig-Ciminska M. The phytoestrogen genistein modulates lysosomal metabolism and transcription factor EB (TFEB) activation. The Journal of biological chemistry. 2014; 289:17054-17069.

40. Malinowska M, Wilkinson FL, Langford-Smith KJ, Langford-Smith A, Brown JR, Crawford BE, Vanier MT, Grynkiewicz G, Wynn RF, Wraith JE, Wegrzyn G, Bigger BW. Genistein improves neuropathology and corrects behaviour in a mouse model of neurodegenerative metabolic disease. PloS one. 2010; 5:e14192.

41. Staquicini FI, Ozawa MG, Moya CA, Driessen WH, Barbu EM, Nishimori H, Soghomonyan S, Flores LG, 2nd, Liang X, Paolillo V, Alauddin MM, Basilion JP, et al. Systemic combinatorial peptide selection yields a noncanonical iron-mimicry mechanism for targeting tumors in a mouse model of human glioblastoma. The Journal of clinical investigation. 2011; 121:161-173.

42. Cervelli T, Palacios JA, Zentilin L, Mano M, Schwartz RA, Weitzman MD, Giacca M. Processing of recombinant AAV genomes occurs in specific nuclear structures that overlap with foci of DNA-damage-response proteins. Journal of cell science. 2008; 121:349-357. 